\title{
Terorisme dan Simalakama Media Massa
}

\author{
Farid Pribadi ${ }^{1}$ \\ Universitas Negeri Surabaya
}

\begin{abstract}
This article discusses the symbiotic relationship of mutualism between mass media and terrorism. Whether we realize it or not, acts of terrorism in the homeland are still interesting and economically valuable news material in front of the mass media. On the other hand, on the part of terrorists, the news about terrorist acts actually becomes a strategic campaign area to show their existence. The research uses a qualitative approach to narrative analysis method. The results of the study are www.okezone.com and www.tribunnews.com placing the terror terror events in Medan Mapolrestabes as interesting and economically valuable news material. The style of the news flow is arranged with a choice of tense, dramatic and sensational nuances of words. In addition, the display of photo and video illustrations shortly after the explosion also aims to display as if the news of the explosion event is true, not engineering, objective and valid. The combination technique of choice of words, story line, placement techniques and the size of photos and videos all aim to make the emotions of the reader participate dissolved in a tense situation as the situation at the scene of the explosion. The practice of compiling this kind of news flow is called, as Jean Baudrillard's practice of simulation. The practice of simulation through the practice of compiling news lines and the touch of visual image technology will eventually create conditions of hyperreality. Namely the conditions between reality will be mixed with the pseudo so it is difficult to distinguish which is original and fake. Next, the airing of a list of victims of unknown origin will actually give birth, as Pierre Bourdie calls it symbolic violence. That is, the practice of violent symbols aimed no longer at the physical target but rather conscious thoughts. Symbolic violence in the appearance of the victim list really has the potential to create traumatic feelings towards the families of the victims.
\end{abstract}

Keywords : Terrorism, Mass Media, Narrative Analysis, Qualitative, Hipperality

\begin{abstract}
Abstrak
Artikel ini membahas hubungan simbiosis mutualisme antara media massa dan terorisme. Entah disadari atau tidak, aksi terorisme di tanah air masih menjadi bahan berita yang menarik dan bernilai ekonomis dihadapan media massa. Disisi lain, dipihak pelaku teror menilai pemberitaan seputar aksi teror justru menjadi lahan kampanye yang strategis untuk menunjukkan eksistensi mereka. penelitian menggunakan pendekatan kualitatif metode analisis naratif. Hasil penelitian adalah www.okezone.com dan www.tribunnews.com menempatkan peristiwa teror edakan di Mapolrestabes Medan sebagai bahan berita yang menarik dan bernilai ekonomis. Gaya alur berita disusun dengan pilihan kata-kata bernuansa mencekam, dramatis dan sensasional. Selain itu, penayangan ilustrasi foto dan video sesaat usai ledakan terjadi juga bertujuan untuk menampilkan seolah-olah berita peristiwa ledakan tersebut benar adanya, bukan rekayasa, objektif dan valid. Teknik perpaduan pilihan katakata, alur cerita, teknik penempatan serta ukuran foto dan video kesemuanya bertujuan agar emosi pembaca turut larut dalam keadaan yang mencekam sebagaimana situasi dilokasi
\end{abstract}

${ }^{1}$ faridpribadi@unesa.ac.id 
kejadian ledakan. Praktik penyusunan alur berita semacam ini yang disebut, sebagaimana Jean Baudrillard sebagai praktik simulasi. Praktik simulasi melalui praktik penyusunan alur berita dan sentuhan teknologi visual gambar akhirnya akan tercipta kondisi hiperrealitas. Yakni kondisi antara kenyataan akan bercampur aduk dengan yang semu sehingga sulit dibedakan lagi mana yang asli dan palsu. Berikutnya penayangan daftar korban yang tidak diketahui asal-usul kebenarannya justru akan melahirkan, sebagaimana Pierre Bourdie menyebut sebagai kekerasan simbolik. Yaitu, praktik kekerasan simbol-simbol yang ditujukan bukan lagi fisik sebagai sasarannya melainkan kesadaran-kesadaran berpikir. Kekerasan simbolik dalam pemunculan daftar korban sesungguh berpotensi melahirkan rasa traumatik terhadap keluarga para korban

Kata Kunci : Terorisme, Media Massa, Analisis Naratif, Kualitatif, Hipperalitas

\section{Pendahuluan}

Ledakan bom kembali terjadi di Indonesia tepatnya terjadi di Markas Polrestabes Medan Sumatera Utara pada Rabu 13 November 2019 sekitar pukul 08.45 waktu setempat. Peristiwa ledakan ini kemudian menjadi perhatian sejumlah media massa baik cetak, elektronik maupun online. Pemberitaan peristiwa ledakan bom seolah mengingatkan kembali serangkaian aksi bom di Indonesia seperti bom Bali tahun 2002 hingga bom di pos penjagaan Kepolisian Polrestabes Surabaya .

Media massa berlomba-lomba membuat headline seputar peristiwa ledakan di markas polisi tersebut. 'Perlombaan' pemberitaan kasus ledakan ini muncul ditengah-tengah perdebatan tentang isu radikalisme. Saat ini masyarakat telah memusatkan perhatiannya kepada kasus bom tersebut melalui media massa, salah satunya melalui media massa online. Pemberitaan kasus ledakan bom yang masif tersebut pada akhirnya mampu menciptakan efek persepsi, dugaan, psikologi dan simbolik berskala global. Globalisasi media sendiri telah menjadikan berbagai aksi terror sebagai tontonan global (global spectacle) yang membentuk pikiran, persepsi dan kesadaran global (Pilliang, 2011).

Menguatnya wacana aksi teror di Indonesia tentu berkaitan dengan aktifitas media massa yang entah disadari atau tidak telah melahirkan hubungan simbiosis mutualisme. Hal ini ditandai ketika media membutuhkan berita yang menarik utnuk diberitakan ke khalayak ramai dan disisi lain para pelaku aksi terror membutuhkan publikasi untuk memperlihatkan eksistensi menyebarkan aksi ideologisnya. 
Kesuksesan aksi teror tidak saja terletak pada tepat atau tidaknya sasaran korban melainkan seberapa luas ancaman aksi teror itu tersebar dan diketahui masyarakat luas. Peneliti isu media dan terorisme bernama Brigitte Nacos (2002) mengemukakan bahwa keberhasilan aksi teroristme memang seringkali bisa diukur dari luasnya peliputan media yang didapatkan. Nacos merumuskan tujuan utama aksi teror yakni mendapatkan perhatian, pengakuan dan rasa hormat pada taraf tertentu (Nacos, 2002).

Kaitan aksi teror dan informasi media massa semacam ini, menurut Yasraf Amir Pilliang merupakan semacam bentuk semiotasi teror (semiotication of terror). Artinya, menjadikan sebuah peristiwa teror sebagai tanda dan tontonan (spectable) lewat berbagai media, dalam rangka menciptakan citra, makna, atau label tertentu tentang seseorang, kelompok masyarakat, atau Negara tertentu. Ketika peristiwa teror terjadi dan kemudian ditampilan di dalam media global maka sesungguhnya ia menjelma menjadi sebuah teks terbuka, yaitu teks (berita, laporan, tontonan, dokumentasi) yang terbuka bagi berbagai penafsiran (Pilliang, 2011).

Hubungan 'simbosis mututalisme' antara aksi teror dan media massa ini pada akhirnya sulit disangkal. Disatu sisi media mendapatkan bahan pemberitaan yang menarik sehingga mampu menarik keuntungan ekonomis, disisi lain para pelaku terorisme mendapatkan 'juru bicara' untuk menyampaikan pesan-pesan mereka. Media massa berusaha menampilkan berita tentang aksi teror semenarik dan seobjektif mungkin, dan disaat bersamaan pelaku teror semakin massif menyebarkan teror kekerasan.

Berdasarkan uraian tentang hubungan 'simbiosis mutualisme' antara pelaku aksi teror dan media massa diatas, peneliti tertarik untuk mengetahui dan memahami bagaimana gaya pemberitaan breaking news aksi teror di Mapolrestabes Medan di media massa online wwe.okezone.com dan www.tribunnews.com 


\section{Metode Penelitian}

Penelitian ini merupakan penelitian kualitatif deskriptif yaitu penelitian yang menggunakan kata-kata sebagai bahasa kajiannya dengan mendeskripsikan hasil analisis yang telah berhasil dilakukan dan dimulai dari dasar dengan memanfaatkan berbagai metode alamiah (Moleong, 2007).

Metode pengumpulan data penelitian ini menggunakan metode studi pustaka yaitu metode pengumpulan dara dengan melakukan penelaahan terhadap berbagai buku, literature, catatan serta berbagai laporan yang berkaitan dengan masalah yang ingin dipecahkan (Nazir, 1988). Subjek penelitian ini adalah berita breaking news tentang ledakan bom di Mapolrestabes di Medan yang terjadi pada Rabu 13 November 2019 di okezone.com dan tribunnews.com. Alasan memilih tiga media massa online tersebut adalah berdasarkan situs perangkingan jumlah pengunjung (visitor) media massa bernama alexa.com tertanggal 10 November 2019 menunjukkan bahwa ranking pertama adalah okezone.com dan kedua tribunnews.com.

Tabel 1. Perangkingan Visitor Media Massa oleh Alexa.com
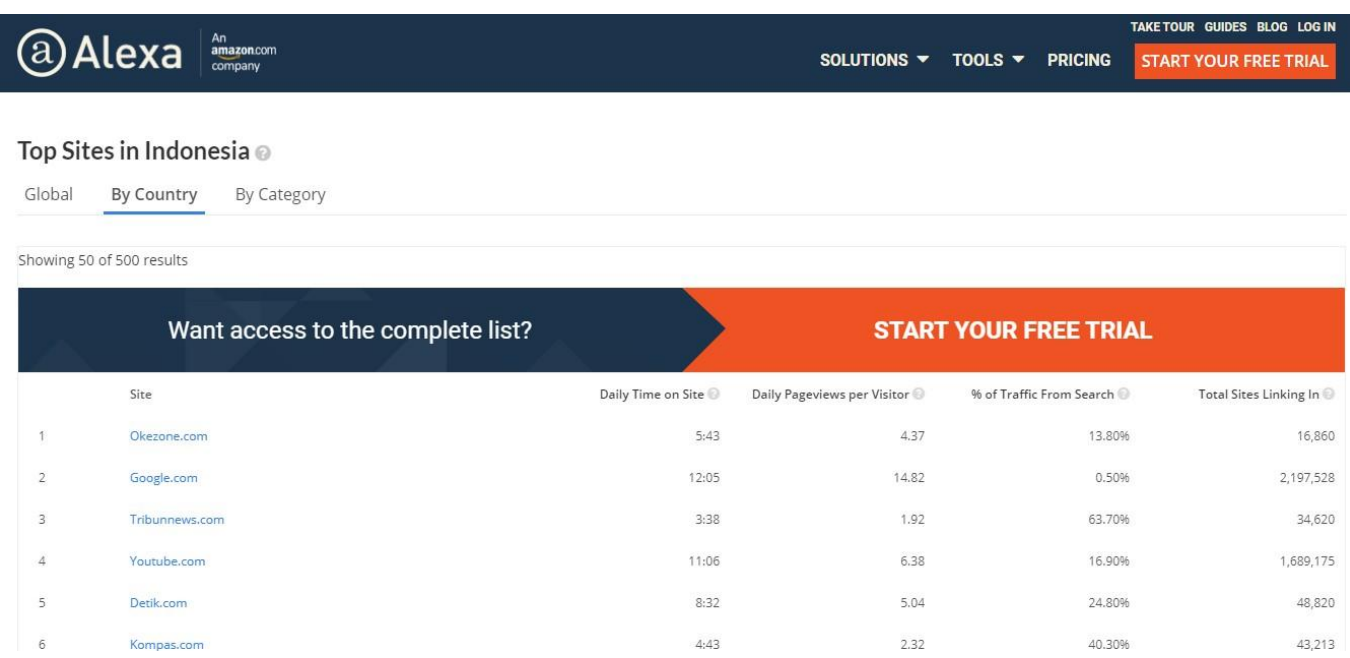

Sumber : https://www.alexa.com/topsites/countries/ID 
Memilih breaking news sebagai fokus analisis teks disebabkan breaking news adalah berita sela atau berita yang sedang berproses. Berita breaking news berisi tentang sebuah peristiwa penting, terjadi sangat cepat, sehingga pemberitaan juga dilakukan cenderung cepat guna mengikuti jalannya peristiwa tersebut. oleh karena demi mengejar kecepatan tadi reporter tidak harus menunggu peristiwa itu sampai tuntas melainkan reporter melaporkan sebuah peristiwa bernilai berita esar secara bertahap. Masing-masing breaking news kasus ledakan bom di Mapolrestabes Medan adalah sebagai berikut:

Tabel 2. Breaking news Kasus Ledakan Bom di Mapolrestabes Medan

\begin{tabular}{|l|l|}
\hline \multicolumn{1}{|c|}{ Situs berita } & \multicolumn{1}{|c|}{ Alamat URL berita kasus bom medan } \\
\hline www.okezone.com & $\begin{array}{l}\text { https://nasional.okezone.com/read/2019/11/13/337/2129 } \\
\text { 162/breaking-news-ledakan-terjadi-di-mapolrestabes- } \\
\text { medan }\end{array}$ \\
\hline www.tribunnews.com & $\begin{array}{l}\text { https://www.tribunnews.com/regional/2019/11/13/breaki } \\
\text { ng-news-ledakan-guncang-markas-polrestabes-medan }\end{array}$ \\
\hline
\end{tabular}

Teknik analisis data yang diadaptasi dalam penelitian ini adalah analisis naratif. Menurut Eriyanto (2013) narasi adalah representasi dari peristiwa-peristiwa atau rangkaian dari peristiwa. Menurut Tzvetan Todorov narasi adalah apa yang dikatakan karenanya mempunyai urutan kronologis, motif dan plot, dan hubungan sebab akibat dari suatu peristiwa. Pembuat narasi disadari atau tidak menyusun teks mempunyai teks ke dalam tahapan atau struktur tersebut, sebaliknya khalayak juga akan membaca anarasi berdasarkan tahapan atau struktur tersebut. Todorov mengemukakan suatu narasi mempunyai struktur dari awal hingga akhir. Narasi diawali dari adanya keseimbangan yang kemudian terganggu oleh adanya kekuatan jahat. Narasi diakhiri oleh upaya untuk mengehntikan gangguan sehingga keseimbangan (ekulibrium) tercipta kembali (Todorov, 1977). 


\section{Hasil dan Pembahasan}

\section{Narasi Berita okezone.com dan tribunnews.com}

www.okezone.com memberitakan kasus ledakan yang terjadi di Mapolrestabes Medan pada hari Rabu 13 November 2019 pada pukul 09.26. berita tersebut diberi judul 'Breaking news : Ledakan Terjadi di Mapolrestabes Medan'

Pada bagian awal Okezone.com menampilkan gambar ilustrasi api ledakan dahsyat yang menghancurkan apapun disekitarnya. Ukuran gambar yang cukup besar jika dibandingkan dengan ukuran teks berita menandakan upaya ledakan yang hebat terjadi. Penggunaan ilustrasi gambar menandakan jurnalis dimungkinkan tidak berada dilokasi kejadian sehingga gambar kondisi terkini saat itu tidak ditampilkan.

Penulis berita bernama Erie Prasetyo menguraikan peristiwa ledakan dengan membagi empat paragraf. Paragram pertama, berisi tentang lokasi dan waktu kejadian ledakan. Paragraf awal ini pembaca ingin ditunjukkan detail lokasi kejadian ledakan yakni di Polrestabes Medan atau markas kepolisian Medan.

MEDAN- Ledakan terjadi di Polrestabes Medan, Jalan HM Said, Kota Medan, Sumatera Utara. Ledakan terjadi pada Rabu 13 November 2019, sekira pukul 08.45 WIB.

Paragraf kedua berisi tentang informasi sementara dari orang-orang disekitar lokasi kejadian tentang kronologis dan terduga pelaku peledakan. Erie sang jurnalis okezone.com berusaha menyuguhkan informasi dari pihak kepolisian. 'pihak kepolisian' tidak disebutkan jelas siapa nama dan jabatan serta posisi saksi dalam peristiwa ledakan tersebut.

Kalimat 'ledakan itu diduga berasal dari bom bunuh diri' menandakan informasi tentang adanya oknum yang berusaha melakukan aksi bom bunuh diri. Kalimat berikutnya '... yang dilakukan dua orang menggunakan atribut ojek online' berusaha menginformasikan tentang adanya dugaan oknum berjumlah dua orang melakukan aksi bom bunuh diri dengan modus menyamar sebagai ojek online. 
Informasi dari kepolisian, ledakan itu diduga berasal dari bom bunuh diri, yang dilakukan dua orang menggunakan atribut ojek online.

Mengandalkan sumber resmi dari pihak kepolisian diatas merupakan upaya jurnalis okezone.com agar pembaca memiliki tafsir tunggal dalam menelaah kasus ledakan tersebut yakni kasus bom bunuh diri. Sehingga meskipun menggunakan kata 'diduga', namun pesan yang ingin sesungguhnya adalah informasi kasus bom bunuh diri adalah aksi nyata, benar dan pasti terjadi. Hal ini juga diperkuat dengan kalimat pernyataan narasumber 'seorang petugas' pada paragraf ketiga "meledak di sekitar kantin Polrestabes Medan, ujar seorang petugas."

Gambar 1. Berita Breaking news Ledakan di Mapolrestabes Medan di Okezone.com

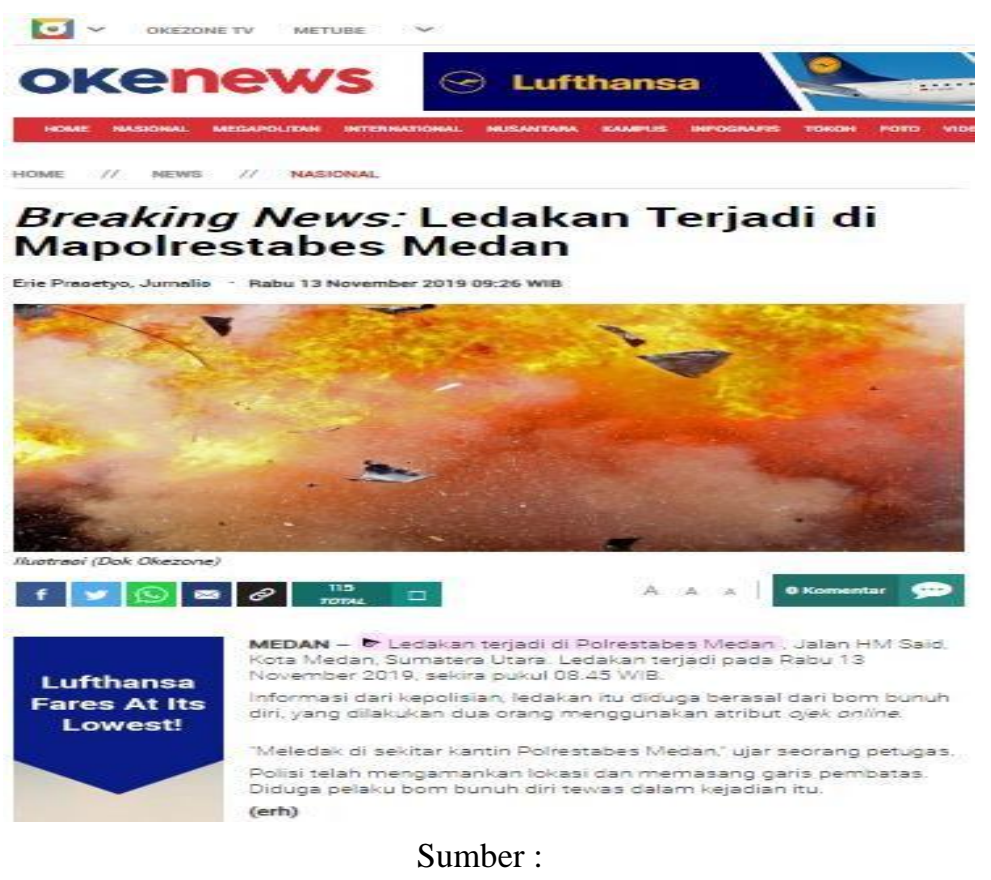

https://nasional.okezone.com/read/2019/11/13/337/2129162/breaking-newsledakan-terjadi-di-mapolrestabes-medan 
Paragraf keempat berisi tentang aktivitas pihak kepolisian yang melakukan pengamanan dilokasi kejadian dengan cara memasang garis pembatas. Pada paragraf terakhir tersebut kata'diduga' juga digunakan untuk mengungkap kondisi oknum pelaku bom bunuh diri yang telah tewas dilokasi kejadian. Teknik menggunakan kata 'diduga' dan diletakkan pada bagian kalimat akhir berita merupakan upaya penggambaran objektif bahwa kondisi oknum peledakan sudah tewas ditempat. Fakta ini telah diteliti oleh pihak kepolisian.

www.tribunnews.com menurunkan berita kasus ledakan dengan judul berita 'Breaking news: Ledakan Guncang Markas Polrestaber Medan'. Berita tersebut dipublikasikan pada Rabu 13 November 2019 pukul 09.24 WIB. Kata 'guncang' dipilih untuk memunculkan kesan dramatis dan sensasional. Kata 'guncang' menurut Kamus Besar Bahasa Indonesia berarti goyah, tidak tetap (berubah-ubah, bergerak-gerak).

Gambar yang digunakan adalah cuplikan gambar tayangan laporan breaking news dari siaran live KompasTV. Tampak seorang jurnalis KompasTV Ferri Irawan sedang menjelaskan kondisi tempat lokasi kejadian. Judul berita yang ditulis KompasTV adalah 'Ledakan Diduga Bom di Polrestabes Medan'. Memilih dan menampilkan gambar dalam ukuran cukup besar tersebut karena KompasTV merupakan salah satu media massa televisi yang juga tergabung dalam Grup Kompas Gramedia bersama tribunnews.com.

Berikutnya menampilkan gambar liputan langsung tersebut merupakan teknik gaya penulisan berita tribunnews.com sebagai upaya objektif bahwa apa yang disajikan merupakan berita yang ditulis langsung dari lokasi kejadian ledakan.

Tribunnews menampilkan ulasan berita cukup detail. Ini ditandai dengan tampilan berita yang terbagi hingga empat bagian halaman. 
Gambar 2. Berita tribunnews.com tentang kasus ledakan di Mapolrestabes Medan (halaman intro)

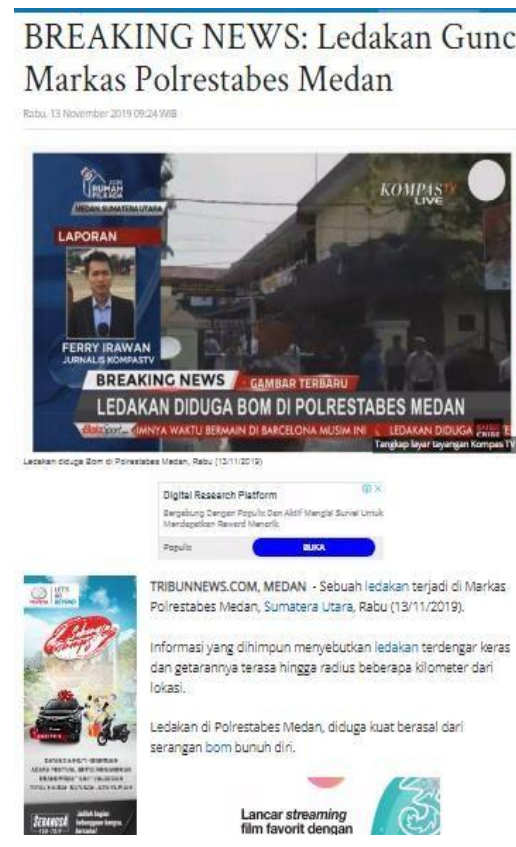

(1)

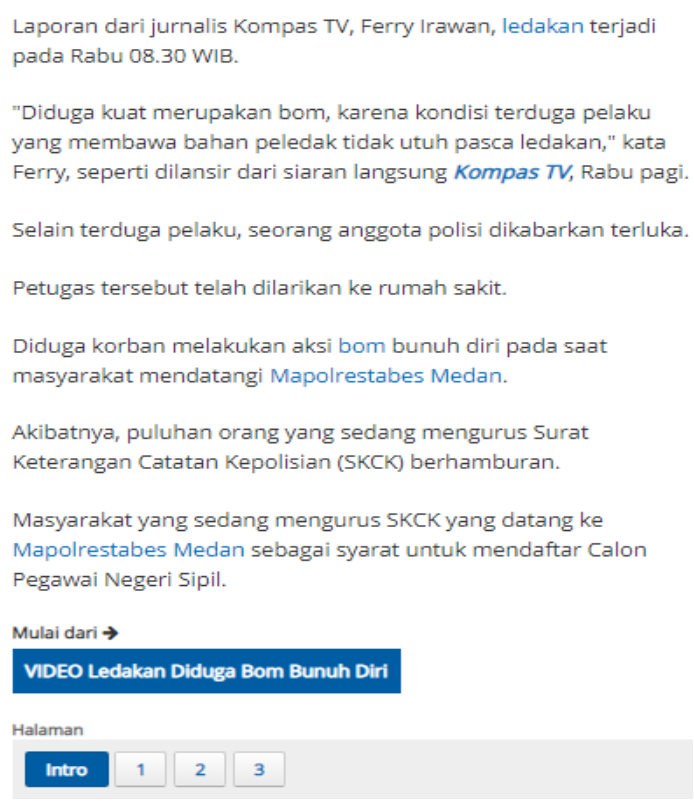

(2)

Berbekal pengutipan instens hasil liputan langsung wartawan KompasTV Ferry Irawan, Tribunnews berusaha detik-detik kondisi terakhir pasca ledakan di Polrestabes Medan, Sumatera Utara Rabu 13 November 2019. Usai menghimpun dari berbagai sumber dilokasi kejadian terdapat beberapa informasi yang ingin disampaikan dibagian pembuka diantaranya kronologis waktu kejadian ledakan, efek ledakan, terduga pelaku dan korban ledakan.

TRIBUNNEWS.COM, MEDAN - Sebuah ledakan terjadi di Markas Polrestabes Medan, Sumatera Utara, Rabu (13/11/2019).

Informasi yang dihimpun menyebutkan ledakan terdengar keras dan gearannya terasa hingga radius beberapa kilometer dari lokasi.

Ledakan di Polrestabes Medan, diduga kuat berasal dari serangan bom bunuh diri. 
Penggunaan kata 'diduga kuat' dianggap tepat merepresentasikan hasil simpulan dari berbagai pihak yang dimintai informasi dan dihimpun sesaat peristiwa ledakan terjadi. Teknik penggunaan kata ini adalah upaya untuk menampilkan berita yang teruji, valid, objektif dan memenuhi unsur $5 \mathrm{~W}+1 \mathrm{H}$.

Berikutnya, dugaan kuat adanya serangan bom bunuh diri dibuktikan dari hasil pengamatan jurnalis KompasTV ketika melihat terdapat seorang oknum yang tidak utuh pasca ledakan dilokasi ledakan.

Pelaku bom bunuh diri melakukan aksinya pada saat masyarakat mendatangi Mapolrestabes Medan untuk mengurus surat keterangan catatan kepolisian (SKCK)

Gambar 3. Berita tribunnews.com tentang kasus ledakan

di Mapolrestabes Medan (halaman 1)

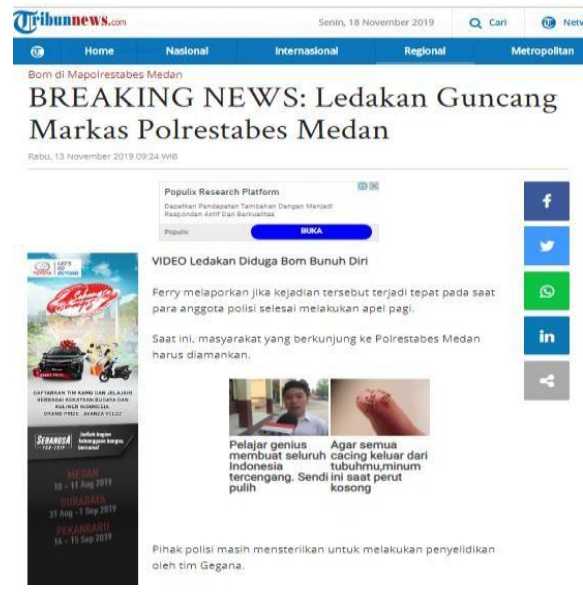

(1)

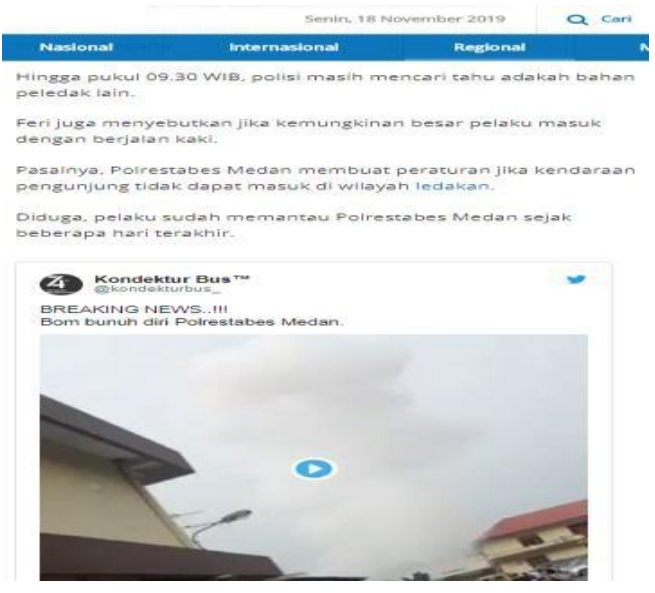

(2)

Pada halaman satu diatas Tribunnews.com memberikan sub judul Video Ledakan Bom Bunuh Diri. Judul tersebut mencoba menguraikan kronologis kejadian ledakan yang terjadi usai para anggota melakukan acara apel pagi. Usai kejadian ledakan masyarakat yang berkunjung ke polrestabes Medan harus diperiksa dengan pengamanan ekstra. Sementara itu lokasi kejadian masih disterilkan oleh tim Gegana. 
Gambar 4. Berita tribunnews.com tentang kasus ledakan di Mapolrestabes Medan (halaman 1 lanjutan)

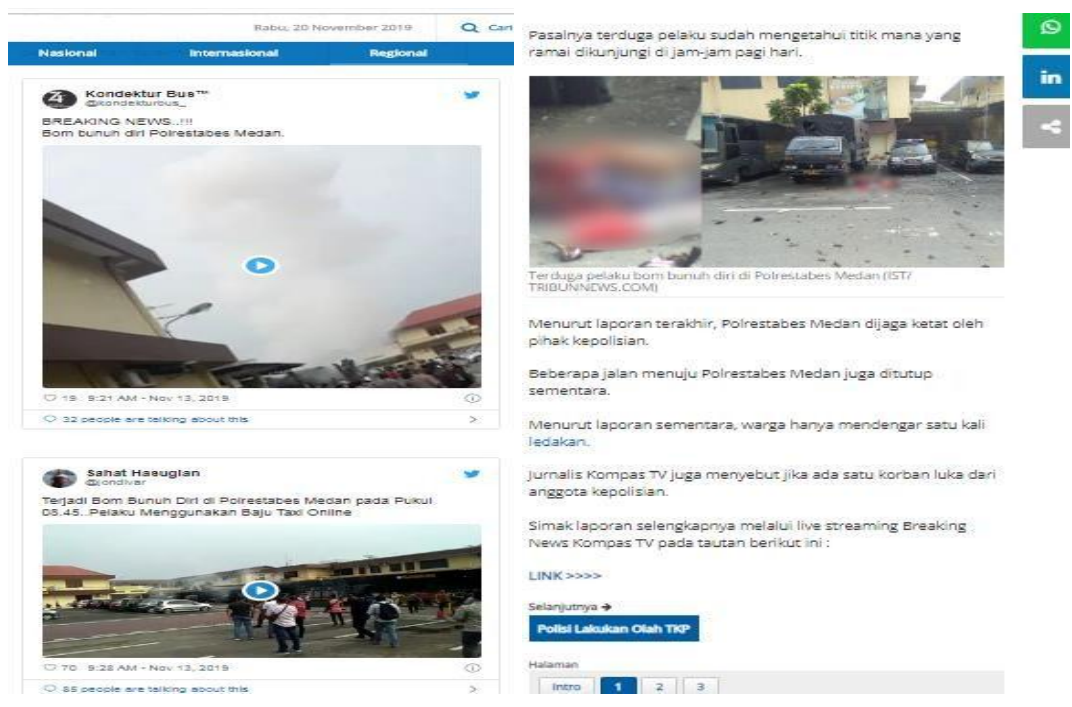

Pada halaman satu juga ditampilkan dua video berisi kondisi terkini Mapolrestabes Medan sesaat ledakan terjadi. Video yang diambil dari netizen dapat diputar oleh pembaca. Di dalam video tergambarkan bagaimana situasi kepanikan dan berbagai sarana-prasarana rusak akibat ledakan. Berikutnya tribunnews.com menampilkan salah satu foto dampak akibat ledakan yakni foto terduga pelaku peledakan. Foto potongan terduga pelaku peledakan ditampilkan dalam ukuran cukup besar namun dikaburkan (diblur). Foto kondisi pelaku peledakan disandingkan dengan kondisi kerusakan beberapa sarana prasarana milik kepolisian. Tampak juga gambar beberapa pecahan kaca yang berserakan dilapangan parkir mobil kepolisian.

Alur cerita pada halaman dua berisi tentang reaksi sigap pihak kepolisian adalah upaya penggambaran bahwa peristiwa ledakan merupakan ancaman serius yang harus segera ditangani. Selain itu penampilan foto situasi di Mapolrestabes untuk menciptakan kesan nuansa mencekam. 
Gambar 5. Berita tribunnews.com tentang kasus ledakan di Mapolrestabes Medan (halaman 2)

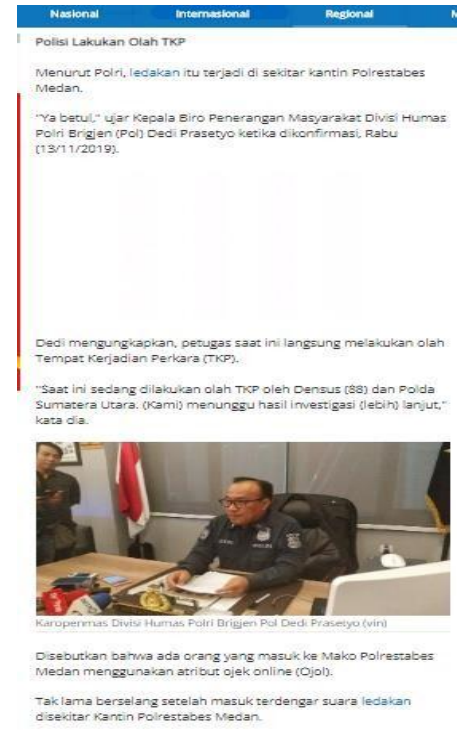

(1)

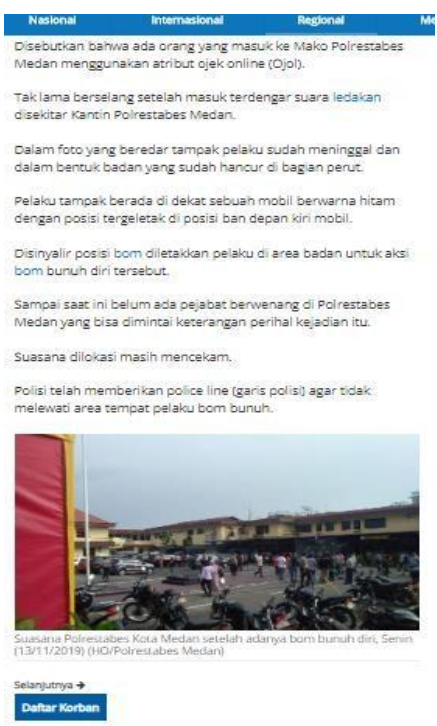

(2)

Halaman dua juga diuraikan bagaimana tanggapan Divisi Humas Polisi Brigen (Pol) Dedi Prasetyo memberikan penjelasan tentang kronologi ledakan. Dijelaskan ledakan terjadi disekitar kantin Mapolrestabes Medan. Oknum terduga pelaku peledakan menggunakan jaket ojek online (ojol). Kondisi terduga pelaku peledakan yang tidak lagi utuh juga diuraikan jelas. Pihak kepolisian Medan dan Tim Gegana 88 memberikan garis polisi di area ledakan.

Di halaman dua juga disuguhkan foto Dedi Prasetyo dan foto kondisi terkini dilokasi kejadian. Foto Divisi Humas Polisi Brigen (Pol) Dedi Prasetyo ditampilkan dalam ukuran besar dengan diberikan keterangan foto 'Karopenmas Divisi Humas Polri Brigjen Pol Dedi Prasetyo'. Foto kedua berisi tentang kondisi pasca ledakan di Mapolrestabes Medan. Foto tersebut dierbikan keterangan 'Suasana Polrestabes Medan setelah adanya bom bunuh diri, Senin (13/11/2019) (HO/Polrestabes Medan). Teknik penampilan dua gambar foto semacam ini adalah upaya tribunnews.com ingin menampilkan bahwa informasi berita tentang kronologi terjadinya ledakan hingga olah TKP bersumber dari pihak resmi negara sehingga 
infromasi tersebut benar-benar valid dan objektif. Foto kedua ditampilkan gambaran kondisi terkini tentang dampak ledakan disekitar Mapolrestabes Medan.

Berdasarkan teknik alur cerita dan peletakkan gambar foto, tribunnews.com ingin menampilkan kesan mencekam, mengerikan, penuh kepanikan, dan mengancam keamanan semua pihak. Selain itu untuk menangani kasus tersebut dibutuhkan kerja sama semua kalangan untuk bersama-sama membasmi aksi teror tersebut.

Gambar 6. Berita tribunnews.com tentang kasus ledakan

di Mapolrestabes Medan (halaman 3)

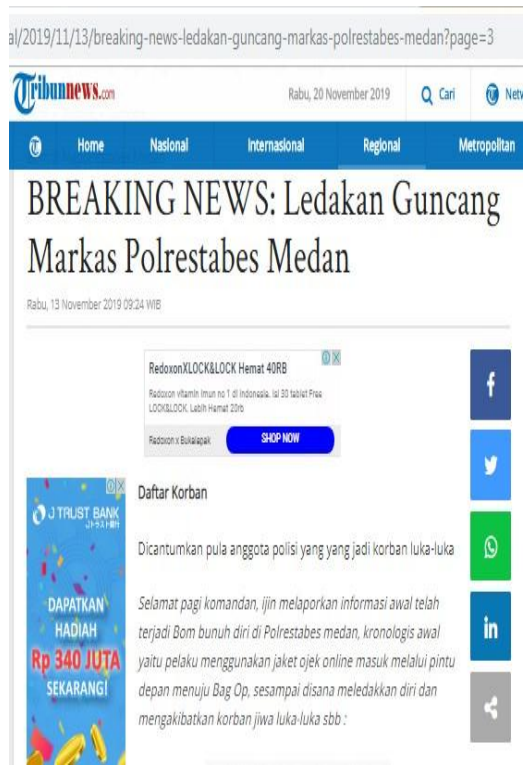

(1)

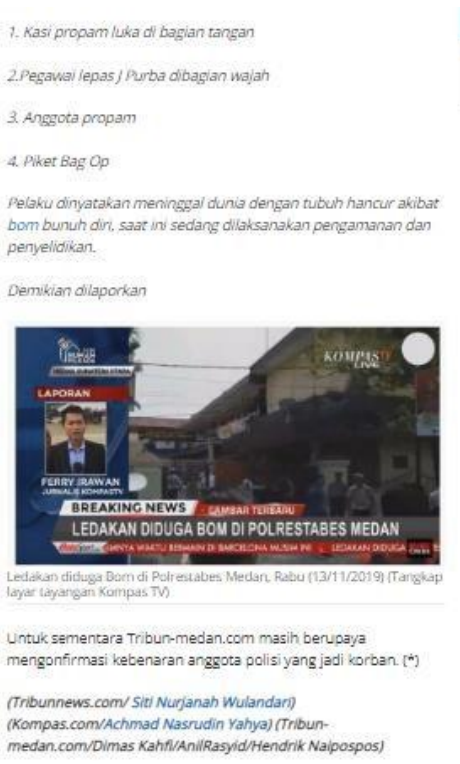

(2)

Pada halaman tiga diberikan sub judul 'Daftar Korban'. Pada bagian akhir berita ini diuraikan beberapa nama korban luka-luka dari pihak kepolisian.

Selamat pagi komandan, ijin melaporkan informasi awal telah terjadi Bom bunuh diridi PolrestabesMedan, kronologis awal yaitu pelaku menggunakan jaket online masuk melalui pintu depan menuju Bag Op, sesampai disana meledakkan diri dan mengakibatkan korban jiwa luka-luka sbb: 
1. Kasi propam luka di bagian tangan

2. Pegawai lepas J Purba dibagian wajah

3. Anggota propam

4. Piket Bag $O p$

Pelaku dinyatakan meninggal dunia dengan tubuh hancur akibat bom bunuh diri, saat ini sedang dilaksanakan pengamanan dan penyelidikan.

Demikian dilaporkan.

Pada halaman terakhir ini penulisan berita dituliskan dengan huruf miring. Teknik penulisan ini bertujuan untuk menggambarkan bahwa informasi dijadikan berita masih dibutuhkan konfirmasi kebenaran lebih lanjut tentang siapa yang menyebarkan. Ketidakjelasan pihak siapa yang menyebarkan daftar korban tersebut kemudian hendak ditindaklanjuti pihak tribunnews.com.

Tribunnews.com berusaha mencari kebenaran daftar koran ditandai dengan penulisan paragraf akhir berita ' Untuk sementara tribun-medan.com masih berupaya mengonfirmasi kebenaran anggota polisi yang jadi korban'. Teknik peletakkan diakhir paragraf dan bukan diletakkan diawal paragraf semacam ini sebagai upaya menciptakan kesan tegang, keprihatinan, dan kemanusiaan. Idealnya dalam etika jurnalistik informasi yang belum benar adanya tidak diperkenankan ditampilkan.

\section{Hiperrealitas Media dan Simalakama Media}

Teror ledakan yang terjadi di Mapolrestabes Medan juga ikut meledak di kanal media massa online. Teror ledakan masih menjadi perhatian besar yang membutuhkan perhatian khusus dari media karena menyangkut keselamatan banyak orang.

Para pelaku aksi teror memiliki tujuan bukan saja pembunuhan atau pengerusakan fisik, melainkan penyebaran rasa takut ataupun ancaman. Pada titik inilah, hubungan media dan terorisme menjadi dilematis. Sebab entah disadari atau tidak keduanya terjalin hubungan simbiosis mutualisme. 
Khalayak membutuhkan media untuk mengetahui peristiwa terorisme. Sebaliknya, pelaku teror membutuhkan media sebagai ruang mempertontonkan eksistensi diri. Kini pelaku teror tak ubahnya bak artis. Menurut pakar isu media dan terorisme Brigitte Nacos (2002) mengemukakan keberhasilan aksi terorisme memang seringkali bisa diukur dari luasnya peliputan media yang didapatkan. Tujuan terorisme menjadi tiga lingkup utama: mendapat perhatian, pengakuan, dan rasa hormat pada taraf terentu. Lebih lanjut, media massa merupakan lahan kampanye yang strategis bagi diskusi dan perdebatan tentang berbagai hal termasuk terorisme (Ross, 2007).

Akan tetapi, entah disadari atau tidak pada sisi pelaku media menempatkan aksi teror berpotensi akan menyedot perhatian besar dan bernilai profit orientied. Sehingga media kerap menampilkan gaya penulisan berita yang sensasional dan dramatis.

Gaya penulisan alur berita yang sensasional dan dramatis peristiwa ledakan di Mapolrestabes Medan baik okezone.com dan tribunnews.com adalah upaya menciptakan kondisi hiperrealitas.

Jean Baudrillard adalah seorang sosiolog Perancis dalam bukunya Simulations (1983) memperkenalkan konsep hiperrealitas merupakan hasil akhir dari suatu kondisi dimana di dalamnya kepalsuan bercampur dengan keaslian, fakta melebur bersama rekayasa, realitas semu dianggap lebih nyata daripada realitas asli, dan kepalsuan dianggap lebih benar daripada kebenaran. Agen pencipta hiperrealitas salah satunya adalah media massa. Media massa sebagai pencipta kondisi hipperrealitas semakin masif jika didukung kecanggihan teknologi informasi.

Penulisan alur cerita ledakan yang terjadi di Mapolrestabes Medan menjadi tiga bagian (awal, tengah, akhir). Awal, berisi tentang berita adanya ledakan. Bagian tengah, berisikan tentang kronologi kejadian ledakan dan dugaan pelaku peledakan. Bagian akhir, tentang gambaran kondisi akibat leddakan dan daftar korban ledakan.

Alur cerita yang disusun dengan pilihan kata-kata yang mampu memacu emosi pembaca seperti 'guncang', 'diduga kuat', 'bom bunuh diri', 'badan yang 
tidak lagi utuh' hingga daftar korban. Nuansa dramatis dan mencekam semakin bertambah dengan manampilkan gambar foto (ilustrasi foto) maupun cuplikan video kondisi terakhir usai ledakan terjadi di Mapolrestabes Medan. Gaya pemberitaan semacam ini jelas justru menempatkan media massa turut serta ikut menebar teror dengan menyebar berita yang mampu meningkatkan keresahan publik.

Hal ini ditandai dengan alih-alih memberikan informasi daftar korban ledakan, media massa justru menjadi corong dari infromasi yang tidak jelas. Sebab daftar nama korban diperoleh dari sumber yang tidak jelas dan lebih terkesan mendapatkan kabar dari desas-desus.

Mengekspos daftar korban yang masih bersifat desas-desus justru terkesan Tribunnews.com telah bertindak eksploitatif dan terkesan berupaya ingin meraih profit semata. Tindakan mengeksploitasi data korban yang masih desas-desus tersebut justru berpotensi menimbulkan rasa traumatik kepada keluarga korban. Keluarga korban yang akan dilanda kepanikan dan diliputi rasa trauma atas kejadian ledakan tersebut. Pada situasi semacam inilah media massa telah melakukan apa yang dikemukakan Pierre Bourdieu (1992) sebagai 'kekerasan simbolik' kepada keluarga korban.

Selain eksploitatif, pemberitaan semacam ini justru berpotensi publik gagal memahami kaitan terorisme. Terorisme tidak mengenal atribut pakaian saat peristiwa teror. Alih-alih meningkatkan kewaspadaan publik pada pelaku teror justru gaya pengungkapan ciri-ciri pelaku teror sebatas pada atribut pakaian saja.

\section{Kesimpulan}

Media massa dan terorisme menjadi dua tema strategis yang menarik perhatian karena memiliki benang merah. Media massa melihat peristiwa terorisme menjadi bahan berita yang menarik untuk mendidik masyarakat agar mawas diri dan bernilai ekonomis. Di sisi pelaku teror, pemberitaan ancaman teror dianggap sebagai media penyebaran eksistensi ideologinya ditengah-tengah masyarakat. Gaya penulisan alur berita terorisme yang hiperrealitas justru mengaburkan fungsi media antara fungsi edukasi peningkatan kewaspadaan publik, namun disisi lain justru media massa dijadikan sebagai lahan kampanye atas aksi 'perjuangan' kelompok 
teror. Gaya pengungkapan fakta dan penulisan berita baik okezone.com dan tribunnews.com tentu menjadi sesuatu hal yang memprihatikan. Kedua media massa daring tersebut idealnya menjadi pemandu bagi publik untuk meyeleksi informasi yang benar. Dalam situasi teror seperti saat ini, peran jurnalis pun di uji kredibiltasnya dalam keikutsertaan mengurangi ancaman teror. Publik pun diharapkan juga tidak mudah percaya kepada berita-berita yang datang silih berganti. Publik harus meyaring terlebih dahulu kebenaran berita tersebut dan terus meningkatkan literasi media.

\section{Daftar Pustaka}

Baudrillard, J. 1983. Simulations. New York: Semiotext (e).

Bourdieu, Pierre. 1992. Language \& Symbolic Power, edited and introduced by JB Thompson, terj. oleh Gino Raymond \& Matthew Adamson. Cambridge: Polity Press.

Eriyanto. 2013. Analisis Naratif: Dasar-dasar dan Penerapannya dalam Analisis Teks Berita Media. Jakarta: Kencana.

https://nasional.okezone.com/read/2019/11/13/337/2129162/breaking-newsledakan-terjadi-di-mapolrestabes-medan

https://www.alexa.com/topsites/countries/ID

https://www.tribunnews.com/regional/2019/11/13/breaking-news-ledakan-guncangmarkas-polrestabes-medan

Moleong, Lexy J. 2007. Metodologi Penelitian Kualitatif. Bandung: PT. Remaja Rosdakarya Offset

Nacos, Brigitte L. 2002. Mass-Mediated Terrorism. USA: Rowman and Littlefield.

Nazir, Mohammad. 1988. Metode Penelitian. Jakarta : Ghalia Indonesia.

Pilliang, Yasraf Amir, 2011. Bayang-Bayang Tuhan Agama dan Imajinasi. Jakarta : Mizan.

Ross, Jeffrey Ian. 2007. Deconstructing The Terrorism News Media Relationship. Journal Crime, Media, Culture 3(2)

Todorov, Tzvetan. 1977. The Poetic of Prose. Translated by Richard Howard. Itacha: Cornell University Press. 